\title{
Remarks on Perspective Simplices
}

G. Weiss

Ret. Professor, Universities of Technology

Dresden and Vienna Institute for Geometry

Austria

H. Ebisui

Priv. Scientist,

Oval Research Centre,

Iwakuni

Japan

The planar figure of two triangles being in perspective position is associated with a theorem of Desargues, which is responsible for the fact that the coordinate set of the plane is a field. This well-known theorem of Desargues allows the obvious interpretation in space of a three-sided pyramid, which is intersected by two planes. The article is dedicated to generalizing this theorem of Desargues to perspective simplices in a projective $n$-space and their linear images in a subspace. Hereby one can find remarkable incidences and configurations. Starting point to this investigation is a planar figure of perspective quadrangles, where the second author discovered a remarkable coincidence figure. The proof of this incidence statement is based on an interpretation of the planar "Ebisui figure" as the central projection of a (projective) cross-polytope in 4-space. This principle can also be extended to higher dimensions.

Keywords: projective space, harmonic homology, Desargues' theorem, simplex, cross polytope, polyhedron. (MSC 2000: 51A20, 51M05)

\section{INTRODUCTION AND EBISUI'S THEOREM}

Let $\pi$ be a projective Desargues plane such that its coordinate field $\mathcal{F}$ has not the characteristic 2 . As a consequence of these assumptions $\pi$ can be immerged into a projective space of dimension $n \geq 3$ and there exist harmonic quadruplets of collinear points. (Plane $\pi$ is a Fano plane, i.e. each quadrangle in $\pi$ has a triangle of diagonal points; confer e.g. [1].) For such a plane $\pi$ the following theorem holds, see also Figure 1.

Theorem 1 ("Ebisui's Theorem"): Let $\left(A_{i}, B_{i}, C_{i}, D_{i}\right)$, $i=1,2$, be two Z-perspective quadrangles of $\pi$. Then the intersection points

$$
\begin{array}{ll}
A_{1} B_{1} \cap A_{2} B_{2}=: E, & C_{1} D_{1} \cap C_{2} D_{2}=: \bar{E}, \\
B_{1} C_{1} \cap B_{2} C_{2}=: F, & D_{1} A_{1} \cap D_{2} A_{2}=: \bar{F}, \\
A_{1} C_{2} \cap A_{2} C_{1}=: G, & B_{1} D_{2} \cap B_{2} D_{1}=: \bar{G},
\end{array}
$$

define three lines $E \bar{E}, F \bar{F}, G \bar{G}$ which are incident with a common point $H$.

(This theorem was communicated by the second author at the „Meeting of the Japan Society for Geometry and Graphics”, Mai 12-13, 2007, Tokyo.)

A simple but lengthy proof of Theorem 1 might use elementary affine vector calculus in $\pi$ assuming that none of the given and calculated points is an ideal point. Of course one will use an affine (or even projective) coordinate frame in $\pi$, which is suitably connected with the given point set $\left\{Z, A_{i}, \ldots, D_{i}\right\}$ to make calculation as simple as possible. But such an analytic proof does not show, where Theorem 1 belongs to and in which way it generalises the well-known Desargues' theorem of

Received: June 2016, Accepted: November 2016

Correspondence to: Prof. Gunter Weiss

Institute for Geometry, Waidhausenstr. 45, A-1140

Vienna, Austria

E-mail: weissgunter@hotmail.com

doi:10.5937/fmet1702243W

(C) Faculty of Mechanical Engineering, Belgrade. All rights reserved perspective triangles. As the Theorem 1 deals only with incidences, it obviously belongs to projective geometry based on a rather general coordinate field $\mathcal{F}$, even it, at first, was stated as a theorem in a Euclidean plane.

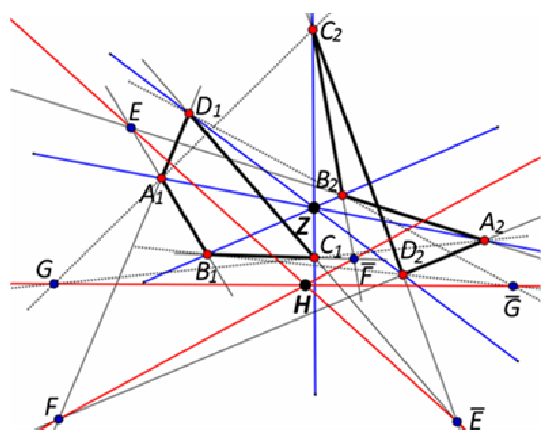

Figure 1. Two perspective quadrangles lead to an "opposite" point $\boldsymbol{H}$ of the perspectivity centre $\boldsymbol{Z}$.

Note that the points $G, \bar{G}$ stem from "overcrossing" pairs of corresponding points of the two sets $\left\{A_{l}, \ldots, D_{l}\right\}$ and $\left\{A_{2}, \ldots, D_{2}\right\}$ and that the Desargues axes of the four pairs of triangles $\left(A_{1} B_{l} C_{l}, A_{2} B_{2} C_{2}\right),\left(B_{l} C_{l} D_{1}, B_{2} C_{2} D_{2}\right)$, $\left(C_{1} D_{1} A_{1}, C_{2} D_{2} A_{2}\right)$, and $\left(D_{1} A_{1} B_{1}, D_{2} A_{2} B_{2}\right)$ form a complete quadrilateral with the six vertices $E \bar{E}, F \bar{F}, G \bar{G}$ !

In the following we interpret the planar figure to Theorem 1 as an image of an object in space, similar to the classical interpretation of the (planar) Theorem of Desargues as linear image of a triangular pyramid, which is intersected by two planes. This allows a proof of Theorem 1 by simple reasoning instead of calculation and it gives a hint, how to generalize it to higher (and even lower) dimensions:

We interpret the planar "Ebisui figure" as the central projection of a cross-polytope in 4-space. Even so one at first might start with a regular cross-polytope in the Euclidean 4-space, the proof holds also for 4-spaces over any field $\mathcal{F}$ with char $\mathcal{F} \neq 2$. Using this idea allows to interpret any (classical) Desargues figure as 
the central projection of a regular octahedron in the projective enclosed Euclidean 3-space. Similarly, as any quadrangle $Q$ can be interpreted as central projection of a square $Q$ ', the quadrangle $Q$ together with its 6 lines, i.e. the 'complete' quadrangle, can be interpreted as the 2-dimensional case of an Ebisui figure.

For dimensions $n>4$ there exist incidence figures, too, but we end up with rather complicated configurations. Anyway, higher dimensional interpretations of perspective simplices and their connection to crosspolytopes still are possible and will result in incidence statements for those cross-polytopes.

\section{DESARGUES' THEOREM AND CENTRAL AXONOMETRY}

The well-known theorem of Desargues concerns two Zperspective triangles and deals with incidences alone. If the place of action is a projective plane $\pi$ such that Desargues' theorem is valid, then $\pi$ is embeddable into a projective 3-space $\Pi$, and the Desargues theorem becomes obvious by the well-known interpretation of the figure as the linear image of an object in $\Pi$, namely of a 3-sided pyramid intersected by two planes, see Figure 2.
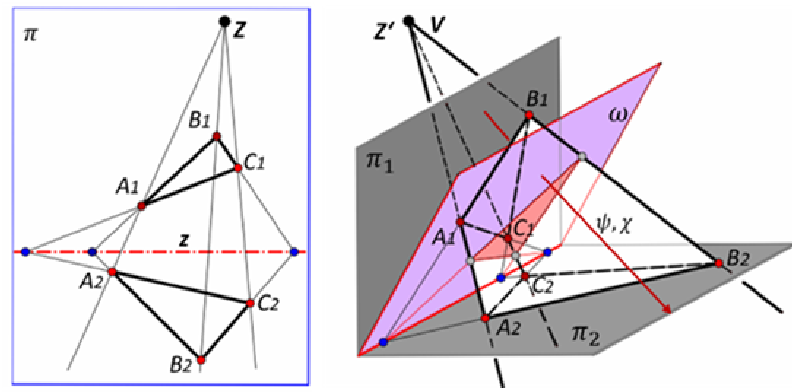

Figure 2. (a) general case of a (labelled) Desargues figure (left) (b) interpretation of (a) as image of an object in 3space, which defines a perspectivity $\Psi$ and a harmonic homology $y$.

If the Desargues axis $z$ of a (labelled) Desargues figure (see Figure 2(a)) does not pass through the perspectivity centre $Z$, this figure defines a homology $\kappa: \pi \rightarrow \pi$ with centre $Z$, axis $z$ and a pair $\left(A_{1}, A_{2}\right)$ of corresponding points. The cross ratio $C R\left(A_{2}, A_{1}, Z, z\right)==: c \in \mathcal{F}$ is called the "characteristic cross ratio" of $\kappa$.

The Desargues figure shows an elation $\kappa: \pi \rightarrow \pi$, if $Z \in z$. In this case a characteristic cross ratio is not defined.

Remark: We distinguish the concepts "Desargues figure" and "Desargues configuration". The $\left(10_{3}, 10_{3}\right)$ configuration of Desargues (Figure 2a) is a set of 10 points and 10 lines and no point (line) is distinguished from any other point (line). The concept characteristic cross-ratio does not make sense for such an "unlabelled" configuration. Taking another point of this configuration as center $Z$ leads (in general) to another characteristic cross ratio value. The relation of all possible characteristic cross ratios to a Desargues configuration is described in [6].

In the 3-space $\Pi$ the pre-image of the planar homology or elation $\kappa$ is a perspectivity $\psi: \pi_{1} \rightarrow \pi_{2}$ of a plane $\pi_{1}$ onto a plane $\pi_{2}$ with the pyramid's vertex $V$ as the perspectivity centre, see Figure 2(b). This perspectivity $\psi$ can be embedded into perspective collineations $\chi: \Pi \rightarrow \Pi$ and there is a one-parametric set of such collineations, as we may choose any plane $\omega$ through $\pi_{1} \cap \pi_{2}$ as fixed plane. Among these collineations $\chi$, for any coordinate field $C R\left(A_{2}, A_{1}, Z, z\right)==: c \in \mathcal{F}$ of char $\mathcal{F} \neq 2$, besides the two singular ones with $\omega=\pi_{1}$ or $\omega=\pi_{2}$ as axis, there are two canonically distinguished regular ones: the elation $\chi_{0}$ with the fixed plane $\left(\pi_{1} \cap \pi_{2}\right) \vee V==: \omega$ and the harmonic homology $\chi_{-1}$ with an axis $\omega$ such that $C R\left(\pi_{2}, \pi_{1}, \mathrm{z} \vee \mathrm{Z}\right.$, $\omega)=-1$. (We supposed $\pi$ to be a Fano plane, therefore harmonic homologies in $\pi$ and in $\Pi$ are well defined regular perspective collineations.)

As we finally aim at the "overcrossings" occurring in Theorem 1 it seems to be natural to consider only the harmonic homology $\chi_{-1}$ as the distinguished collineation within the set of all perspective collineations belonging to $\psi$.

Let us at first consider a classical Desargues figure in a projective plane $\pi$ which we at first embed into a projective enclosed affine 3-space $\Pi_{\alpha}$. The basic figure of two $Z$-perspective triangles $\left\{Z ; A_{1}, B_{1}, C_{1} ; A_{2}, B_{2}, C_{2}\right.$ ) $\subset \pi$ can be interpreted as the fundamental figure of a central axonometry $\alpha: \Pi_{\alpha} \rightarrow \pi$.

Remark: „central axonometry“ means a linear mapping of a space $\Pi$ onto an image plane $\pi$ based on a projective coordinate frame in $\Pi$ and its linear image figure, which usually is called the "axonometric fundamental figure", (see e.g. [2], [3], [4] and [5]). Extensions to higher dimensions are obvious.

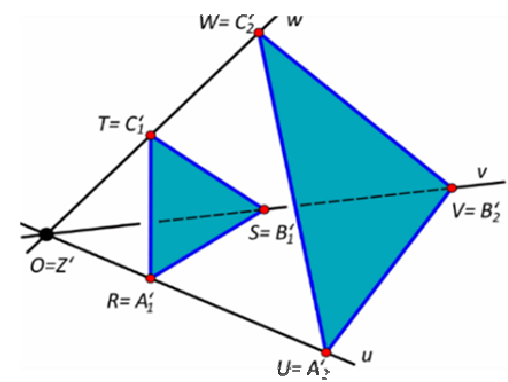

Figure 3. An axonometric fundamental figure connected with a Desargues figure.

Thereby $Z=: O^{\alpha}$ is the image of the origin $O$ in space, furthermore we use $A_{l}, B_{l}, C_{1}$ as the images of "unit points" $R=A_{1}^{\alpha^{-1}}, S=B_{1}^{\alpha^{-1}}, T=C_{1}^{\alpha^{-1}}, \quad$ and interpret $A_{2}, B_{2}, C_{2}$ as the images of "ideal points" $U=A_{2}^{\alpha^{-1}}, V=B_{2}^{\alpha^{-1}}, W=C_{2}^{\alpha^{-1}}$ of the "coordinate axes" $u, v, w \subset \Pi$ through $O$, see Figure 3 .

The "unit plane" $\varepsilon=R S T$ intersects the "ideal plane" $v=U V W$ in the pre-image of the Desargues axis $z$ of the two $Z$-perspective triangles. Thus the fixed plane $\omega$ of the harmonic homology $\chi_{-1}$ intersects $u, v, w$ in the "negative unit points" $R^{-}, S^{-}$and $T$.

Remark: As we are free in choosing $\Pi_{\alpha}$ and its ideal elements, we could have started with a projective space $\Pi$ and an axonometry such that $R^{-}, S, T$ become the pre-images of $A_{2}, B_{2}, C_{2}$. Then the fixed plane $\omega$ of the above mentioned harmonic homology $\chi_{-1}$ automatically acts as the "ideal plane". Furthermore, if we assume that 
$\mathcal{F}$ is a Euclidean field, then $(\Pi, \omega)$ allows an interpretation as a projective enclosed Euclidean space and $R, S, T, R^{-}, S, T$ become the vertices of a regular octahedron with centre $O$. We collect this as:

Theorem 2: Let $\pi$ be a projective plane over the field $\mathcal{F} \approx \mathbb{R}$ and $A_{1}, B_{1}, C_{1}$ and $A_{2}, B_{2}, C_{2}$ two $Z$ perspective triangles in $\pi$. Then $\left\{Z ; A_{1}, B_{1}, C_{1} ; A_{2}, B_{2}\right.$, $\left.C_{2}\right\} \subset \pi$ can always be interpreted as the central axonometric image of midpoint and vertices of a (Euclidean) regular octahedron.

\section{THEOREM 1 AND CENTRAL AXONOMETRY}

Let us now turn back to the planar configuration of two $Z$-perspective quadrangles $\left(A_{i}, \ldots, D_{i}\right), i=1,2$ as described in Theorem 1. Analog to Theorem 2 we now interpret this labelled configuration as the central axonometric image of an affine regular cross-polytope $\mathrm{P}_{8}$ in the projectively extended four-dimensional affine space $\Pi_{\alpha}^{4}$ over the field $\mathcal{F}$.

Again we interpret the two Z-perspective planar quadrangles at first as linear images of two $O$-perspective tetrahedra, each spanning a hyperplane $\Pi_{1}$ resp. $\Pi_{2} \subset \Pi_{\alpha}^{4}$. We now embed the O-perspectivity $\psi: \Pi_{1} \rightarrow$ $\Pi_{2}$ into a harmonic homology $\chi: \Pi_{\alpha}^{4} \subset \Pi_{\alpha}^{4}$ with centre $O$ (the pre-image of $Z$ ) and with a certain hyperplane $\Omega$ as the fixed axis of $\chi$. Let us choose $\Omega$ as the ideal hyperplane of $\Pi_{\alpha}^{4}$ such that $O$ is a proper point of $\Pi_{\alpha}^{4}$. Then, by using the originals $O$ and $A_{1}^{\prime}, \ldots, D_{1}^{\prime} \in \Pi_{\alpha}^{4}$ of $Z$, $A_{1}, \ldots, D_{1} \in \pi$ as origin and unit points of a coordinate frame, we receive very simple projective coordinates of the points of the entire configuration, namely:

$$
\begin{gathered}
A_{i}^{\prime}=(1, \pm 1,0,0,0) \mathcal{F}, \quad B_{i}^{\prime}=(1,0, \pm 1,0,0) \mathcal{F}, \\
C_{i}^{\prime}=(1,0,0, \pm 1,0) \mathcal{F}, \quad D_{i}^{\prime}=(1,0,0,0, \pm 1) \mathcal{F}, \\
Z^{\prime}=(1,0,0,0,0) \mathcal{F}, i=1,2 .
\end{gathered}
$$

Therewith we get the originals (c.f. (1)) $E^{\prime}, \bar{E}^{\prime}, F^{\prime}$, $\bar{F}^{\prime}, G^{\prime}, \bar{G}^{\prime}$ of $E, \ldots, \bar{G}$ almost without any calculation as:

$$
\begin{aligned}
& E^{\prime}=(0,1,-1,0,0) \mathcal{F}, \quad \bar{E}^{\prime}=(0,0,0,1,-1) \mathcal{F}, \\
& F^{\prime}=(0,0,-1,1,0) \mathcal{F}, \quad \bar{F}^{\prime}=(0,1,0,0,-1) \mathcal{F}, \\
& G^{\prime}=(0,1,0,1,0) \mathcal{F}, \quad \bar{G}^{\prime}=(0,0,1,0,1) \mathcal{F},
\end{aligned}
$$

and finally

$$
\begin{aligned}
E^{\prime} \bar{E}^{\prime}= & \{(\lambda(0,1,-1,0,0)+\bar{\lambda}(0,1,-1,0,0)) \mathcal{F}\}, \\
F^{\prime} \bar{F}^{\prime}= & \{(\mu(0,1,0,0,-1)+\bar{\mu}(0,0,1,-1,0)) \mathcal{F}\}, \\
G^{\prime} \bar{G}^{\prime}= & \{(v(0,1,0,1,0)+\bar{v}(0,0,1,0,1)) \mathcal{F}\}, \\
& (\lambda, \bar{\lambda}),(\mu, \bar{\mu}),(v, \bar{v}) \subset \mathcal{F}^{2} \backslash(0,0)
\end{aligned}
$$

These three lines (4) intersect in a common point:

$$
E^{\prime} \bar{E}^{\prime} \cap F^{\prime} \bar{F}^{\prime} \cap G^{\prime} \bar{G}^{\prime}=: H^{\prime}=(0,1,-1,1,-1) \mathcal{F}
$$

As the three lines $E^{\prime}, \bar{E}^{\prime}, F^{\prime}, \bar{F}^{\prime}, G^{\prime}, \bar{G}^{\prime}$ of $\Omega \subset \Pi_{\alpha}^{4}$ indeed coincide with a common point $H^{\prime}$, any linear image of them must have the same property, i.e. the $\alpha$ images $E \bar{E}, F \bar{F}, G \bar{G}$ of these lines are concurrent with a point $H=H^{\alpha}$. Therewith we have proved

Theorem 3: Let be given a labelled planar "Ebisui figure" consisting of two Z-perspective quadrangles $\left(A_{i}\right.$, $\left.B_{i}, C_{i}, D_{i}\right), i=1,2$ together with centre $\mathrm{Z}$ and the intersection points $E, \ldots, \bar{G}$ according to Theorem 1 .

- Then $\left\{Z ; A_{1}, . ., D_{1} ; A_{2}, \ldots, D_{2}\right\}$ can always be interpreted as the linear image (central axonometric image) of an affine regular cross-polytope $\mathrm{P}_{8}$ with vertices $\left\{A_{1}^{\prime}, \ldots\right.$, $\left.D_{2}^{\prime}\right\}$ and centre $Z^{\prime}$ in a four-dimensional projective extended affine space $\Pi_{\alpha}^{4}$.

- Furthermore, the originals $E^{\prime}, F^{\prime}, G^{\prime}$ and $\bar{E}^{\prime}, \bar{F}^{\prime}, \bar{G}^{\prime}$ of $E, \ldots, \bar{G}$ form two perspective triangles in the ideal hyperplane $\Omega$ of $\Pi_{\alpha}^{4}$ with a point $H^{\prime}$ as their Desargues centre, which maps onto the remarkable "Ebisui-point" $H$ of the given Ebisui figure.

Remark 1: Obviously, if $\Pi_{\alpha}^{4}$ is taken as a projective enclosed Euclidean 4-space, then $\mathrm{P}_{8}$ can be interpreted as a Euclidean regular cross-polytope.

Remark 2: Note that central axonometry maps a point $P^{\prime}$ of the $n$-space to a point $P$ of an image $k$-space or plane using the so-called coordinate path with respect to the axonometric base figure. The coordinate path uses the projective coordinates of $P^{\prime}$, therefore it is not necessary to distinguish between the original $P^{\prime}$ and their axonometric image $P$ in terms of coordinates. In the following we therefore will omit to use different labelling for originals and their images, as it will come clear from the text what is meant.

\section{COMPLETE QUADRANGLES AS THE TWO- DIMENSIONAL CASE: FANO'S FIGURE}

Instead of perspective triangles in a projective Fano-plane $\pi$ and its interpretation as (central) axonometric image of an octahedron let us now consider two line segments $s_{1}:=$ $\left(A_{1}, B_{1}\right) s_{2}:=\left(A_{2}, B_{2}\right) \subset \pi$ such that the endpoints of those segments form a quadrangle. These labelled segments define a unique perspectivity centre $Z$ (see Fig. 4). Interpretation in space now degenerates to an interpretation in a projective enclosed affine (resp. Euclidean) plane $\pi$ : $\left(A_{1}, \ldots, B_{2}\right)$ are linear axonometric images of the vertices $\left(A_{1}^{\prime}, \ldots, B_{2}^{\prime}\right)$ of a parallelogram (resp. a square); thereby point $Z$ is the image of its centre $Z^{\prime}$.

Again we embed the perspectivity $\psi: s_{1}^{\prime} \rightarrow s_{2}^{\prime}$ into a harmonic homology $\chi: s_{1}^{\prime} \rightarrow s_{2}^{\prime}$ and its axis $z^{\prime}$ passes through point $S^{\prime}:=A_{1}^{\prime} B_{1}^{\prime} \cap A_{2}^{\prime} B_{2}^{\prime}$ and it contains the intersection $G^{\prime}$ of "overcrossing lines" $A^{\prime}{ }_{1} B_{2}{ }_{2}, A_{2}^{\prime} B_{1}{ }_{1}$. The axonometry $\alpha: \pi^{\prime} \rightarrow \pi$ is simply a projective collineation, we receive $C R\left(A_{1} B_{1}, A_{2} B_{2}, Z, z\right)$, what is a trivial property of complete quadrangles in a Fano plane $\pi$.

As a trivial result we state:

Theorem 4: A labelled complete quadrangle in a projective Fano plane allows an interpretation as the two-dimensional (degenerated) case of a general Desargues figure in the sense of $\mathrm{H}$. Ebisui. 


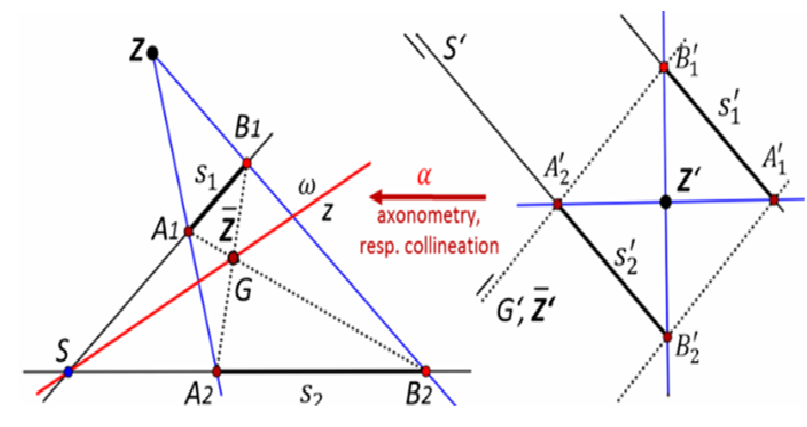

Figure 4. Two generally positioned labelled segments spanning a plane are trivially in perspective position and they give rise to a FANO figure as the two-dimensional case of Ebisui's construction.

\section{EBISUI-POINTS OF PERSPECTIVE TETRAHEDRA AND COMPLETE QUADRANGLES}

Already the four-dimensional case has to consider two subcases: the one described in Theorem 3 and one, where we start with a pair of perspective skew quadrangles in a 3space $\Pi^{3}$. Also this figure is a proper axonometric basis figure for an axonometry $\alpha: \Pi_{\alpha}^{4} \rightarrow \Pi^{3}$ and therefore we can use the same calculation as for Theorem 3 receiving the same point $H^{\prime} \in \Pi_{\alpha}^{4}$ as result.

Again we state as a:

Theorem 5: Let two labelled skew quadrangles in a 3-dimensional projective Fano space be given in perspective position. Then the three lines $E \bar{E}, F \bar{F}, G \bar{G}$ defined according to Theorem 1 have a common point $H$. Remark 1: Two labelled tetrahedra in perspective position or two planar complete quadrangles in perspective position give rise to three pairs of edge quadrilaterals and each pair leads to an Ebisui point $H_{k}$, $k=1,2,3$. This combinatorial approach, which we also want to apply to higher dimensions, makes a relabelling of the quadrangles necessary:

Table 1. (Axonometric) projective coordinates of the Ebisuipoints $\boldsymbol{H}^{i}$ to perspective tetrahedra.

\begin{tabular}{|l|l|l|}
\hline $\begin{array}{l}\text { Case 1: quadrangle } \\
\left(A_{1}, A_{2}, A_{3}, A_{4}\right)\end{array}$ & $\begin{array}{c}\text { Case 2: quadrangle } \\
\left(A_{1}, A_{2}, A_{3}, A_{4}\right)\end{array}$ & $\begin{array}{c}\text { Case 3: quadrangle } \\
\left(A_{1}, A_{2}, A_{3}, A_{4}\right)\end{array}$ \\
\hline $\mathrm{D}_{22}=(0,1,-1,0,0) \mathcal{F}$ & $\mathrm{D}_{22}=(0,1,-1,0,0) \mathcal{F}$ & $\mathrm{D}_{24}=(0,0,1,0,-1) \mathcal{F}$ \\
$\mathrm{D}_{24}=(0,0,0,1,-1) \mathcal{F}$ & $\mathrm{D}_{24}=(0,0,0,1,-1) \mathcal{F}$ & $\mathrm{D}_{22}=(0,1,0,-1,0) \mathcal{F}$ \\
\hline $\mathrm{D}_{22}=(0,1,0,-1,0) \mathcal{F}$ & $\mathrm{D}_{24}=(0,0,1,0,-1) \mathcal{F}$ & $\mathrm{D}_{22}=(0,0,1,-1,0) \mathcal{F}$ \\
$\mathrm{D}_{24}=(0,0,1,0,-1) \mathcal{F}$ & $\mathrm{D}_{22}=(0,1,0,-1,0) \mathcal{F}$ & $\mathrm{D}_{24}=(0,1,0,0,-1) \mathcal{F}$ \\
\hline $\mathrm{O}_{22}=(0,1,0,1,0) \mathcal{F}$ & $\mathrm{O}_{24}=(0,1,0,0,1) \mathcal{F}$ & $\mathrm{O}_{22}=(0,1,1,0,0) \mathcal{F}$ \\
$\mathrm{O}_{24}=(0,1,0,1,0) \mathcal{F}$ & $\mathrm{O}_{22}=(0,0,1,1,0) \mathcal{F}$ & $\mathrm{O}_{24}=(0,0,0,1,1) \mathcal{F}$ \\
\hline$H^{2}=(0,1,-1,1,-1) \mathcal{F}$ & $H^{2}=(0,1,-1,-1,1) \mathcal{F}$ & $H^{2}=(0,1,1,1,1) \mathcal{F}$ \\
\hline$Z=(1,0,0,0,0) \mathcal{F}, G=\mathrm{O}_{13} \mathrm{O}_{24} \cap \mathrm{O}_{14} \mathrm{O}_{24} \cap \mathrm{O}_{12} \mathrm{O}_{34}=(0,1,1,1,1) \mathcal{F}$ \\
\hline
\end{tabular}

In the following we label the points of the first quadrangle with $A_{i}, i=1, \ldots, 4$ and those of the second quadrangle with $B_{i}, i=1, \ldots, 4$ The "direct Desargues points" mean $A_{i} A_{j} \cap B_{i} B_{j}=: D_{i j}$, while Desargues points stemming from "overcrossings" are labelled by $O_{i j}:=$ $A_{i} B_{j} \cap B_{i} A_{j}$. We will also use the "ideal points" $C_{i}$ of lines $Z A_{i}$ and being harmonic to $Z$ with respect to the pairs $\left(A_{i}, B_{i}\right)$.The points $C_{i}$ form a simplex (i.e. a tetrahedron) in the ideal hyperplane, i.e. a 3-space and have $\left(0, \delta_{1 i}, \delta_{2 i}, \delta_{3 i}, \delta_{4 i}\right) F$ as projective coordinates.

We list the three cases with the corresponding figures and coordinates below (Table 1, Figures 5 and 6):

From Table 1 we read off that there occur only six different points $D_{i j}$, and they are the vertices of a complete quadrilateral, the sides of which are the Desargues axes of the four pairs of partial triangles of the given pair of quadrangles resp. tetrahedra.

The three Ebisui-points $H^{k}$ are the diagonal points of the above mentioned quadrilateral (Figure 5).

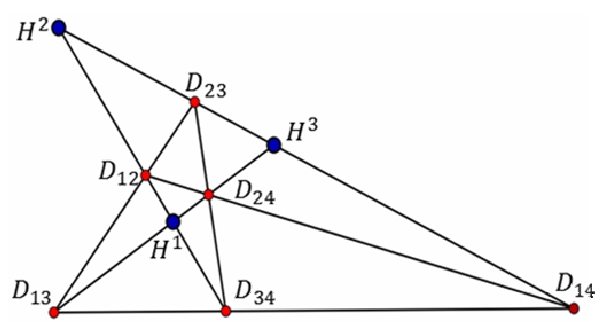

Figure 5. Configuration of intersection points $D_{i j}$ of corresponding sides of perspective tetrahedra and their three Ebisui points $\boldsymbol{H}^{k}$.

In addition we can state:

Theorem 6: Given two tetrahedra or two planar quadrangles in perspective positions, then the three lines $\mathrm{O}_{13} \mathrm{O}_{24}, \mathrm{O}_{14} \mathrm{O}_{24}, \mathrm{O}_{12} \mathrm{O}_{34}$ stemming from "over-crossings" meet in a common point $G=(0,1,1,1,1) \mathcal{F}$. The three Ebisui-points $H^{k}$ together with $G$ have (axonometric) projective coordinates, which can be interpreted as vertices of a regular tetrahedron in the ideal hyperplane of a projectively enclosed affine 4-space $\Pi_{\alpha}^{4}$.

We show the mutual incidences described in Theorem 6 in an axonometric view of that ideal hyperplane of $\Pi_{\alpha}^{4}$ in Figure 6.

Remark 2: Among other incidences we find that the lines $\mathrm{D}_{12} \mathrm{O}_{34}, \mathrm{D}_{13} \mathrm{O}_{24}$ and $\mathrm{D}_{14} \mathrm{O}_{23}$ have a common point $F^{1}=(0,-1,1,1,1) F$ and similarly

$$
\begin{aligned}
& D_{12} O_{34} \cap D_{23} O_{14} \cap D_{24} O_{13}=\mathcal{F}^{2}=(0,1,-1,1,1) \mathcal{F}, \\
& D_{13} O_{24} \cap D_{23} O_{14} \cap D_{34} O_{12}=\mathcal{F}^{3}=(0,1,1,-1,1) \mathcal{F}, \\
& D_{14} O_{23} \cap D_{24} O_{13} \cap D_{34} O_{12}=\mathcal{F}^{4}=(0,1,1,1,-1) \mathcal{F} .
\end{aligned}
$$

The simplices $\left(\mathcal{F}^{1}, \ldots, \mathcal{F}^{4}\right)$ and $\left(C^{1}, \ldots, C^{4}\right)$ are $G$ perspective, while $\left(\mathcal{F}^{1}, \ldots, \mathcal{F}^{4}\right)$ and $\left(G, H^{1}, H^{2}, H^{3}\right)$ are not only $C_{1}$-perspective, but also $\mathrm{C}_{\mathrm{i}}$-perspective, see Figure 6. Remark 3: The points $O_{i j}$ can be interpreted as vertices of an octahedron with centre $G$. We also recognize that, within the ideal hyperplane of $\Pi_{\alpha}^{4}$, i.e. a 3-space $\Pi_{\omega}^{3}$, this octahedron defines a Desargues configuration and e.g. a perspectivity $\psi_{3}$ with centre $G$ mapping the triangle $\left(\mathrm{O}_{12} \mathrm{O}_{13} \mathrm{O}_{14}\right)$ onto the triangle $\left(\mathrm{O}_{23} \mathrm{O}_{34} \mathrm{O}_{24}\right)$ and again $\psi_{3}$ can be embedded into a harmonic homology $\chi_{3}$ with axis plane spanned by the complete quadrilateral $\left\{D_{i j}\right\}$, see Fig. 5. The three collinear points $D_{34}, D_{24}, D_{23}$ 
span the Desargues axis of the perspectivity $\psi_{3}$, i.e. the lines $\mathrm{O}_{12} \mathrm{O}_{13}$ and $\mathrm{O}_{34} \mathrm{O}_{24}$ meet at $\mathrm{D}_{23}$, and so on. But there are altogether four possibilities of such perspectivities resp. homologies and each side of the complete quadrilateral $\left\{D_{\mathrm{ij}}\right\}$ acts as Desargues axis of each of these perspectivities.

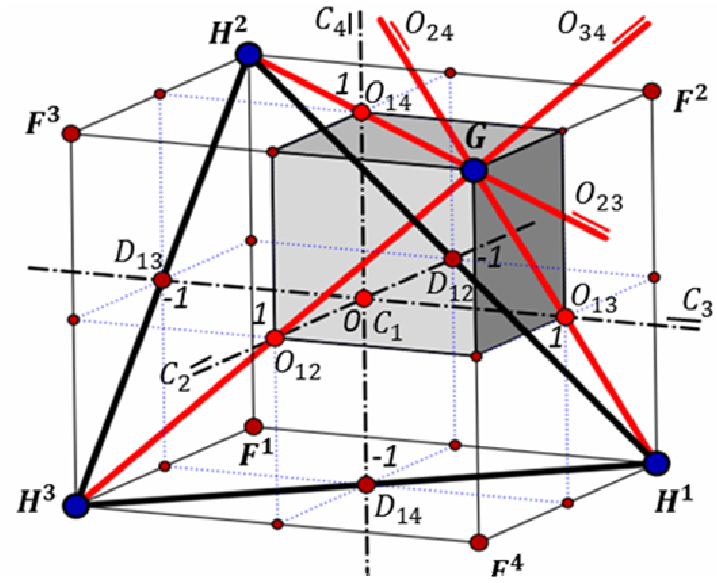

Figure 6. Configuration of intersection points $O_{i j}$ of "overcrossing" connecting sides of perspective tetrahedra and their three Ebisui points $H^{k}$.

Our cross-polytope $\mathrm{P}_{8}$, which realises a perspectivity $\psi_{4}$ between two opposite face tetrahedra and the canonically defined harmonic homology $\chi_{4}$ to $\psi_{4}$, induces an octahedron $\mathrm{P}_{6}$ in the (ideal) axis hyperplane of $\chi_{4}$. This octahedron again delivers the classical situation of a Desargues figure as treated in Chapter 2 with the two-dimensional case of a complete quadrangle in the axis plane of $\chi_{3}$, see Chapter 4 . In the following we shall see that this hierarchical structure also holds for higher-dimensional cases.

\section{HIGHER-DIMENSIONAL CASES}

The idea of interpreting the planar figures as axonometric image of a square, an octahedron or a cross-polytope $\mathrm{P}_{8}$ suggests to consider pairs of closed polygons with $p$ vertices in perspective position in a given classical projective $k$-space $\Pi^{k}$ and interpret them as the central axonometric image of a cross-polytope $\mathrm{P}_{2 \mathrm{p}}$ in an $n$-dimensional affine (resp. Euclidean) space $\Pi_{\alpha}^{p}$ with an "ideal hyperplane" $\Pi_{\omega}^{p-1}$ as projective enclosure. The polygons $\left(A_{1}, \ldots, A_{p}\right)$ and $\left(B_{1}, \ldots, B_{p}\right)$ together with centre $Z$ give reason to $\left(\begin{array}{l}p \\ 4\end{array}\right)$ quadrangles and each of them lead to three Ebisui-points and one point $G$. There occur $\left(\begin{array}{l}p \\ 2\end{array}\right)$ direct Desargues points $\mathrm{Dij}=$ $A_{i} A_{j} \cap B_{i} B_{\mathrm{j}}$ and $\left(\begin{array}{l}p \\ 2\end{array}\right)$ points $O_{i j}$ stemming from "overcrossing" lines $A_{i} B_{j}, A_{j} B_{i}$. Interpreting the points of the two polygons as vertices of $\mathrm{P}_{2 \mathrm{p}}$ with centre $Z$ (- we use the same symbols for points in $\Pi^{\mathrm{k}}$ and in $\Pi_{\alpha}^{p}-$ ) the points $D_{i j}$ and $O_{i j}$ as well as the Ebisui-points and the points of type $G$ span the ideal hyperplane $\Pi_{\omega}^{p-1}$. The $p$ intersections of $\Pi_{\omega}^{p-1} \cap Z A_{i}=: C_{i}$ can be used to define a coordinate frame in $\Pi_{\omega}^{p-1}$. The three hyperplanes $\Pi_{\omega}^{p-1}, \Pi_{A}^{p-1}, \Pi_{B}^{p-1}$, spanned by $\left\{C_{i}\right\} .\left\{A_{i}\right\}$ resp. $\left\{B_{i}\right\}$ intersect in a space $\Pi_{\omega}^{p-2}$ spanned by the set $\left\{D_{i j}\right\}$, see Figure 7 .

In the following we present only the case $p=5$ as an example. It illustrates already the occuring incidences and configurations also for arbitrary cases of $\mathrm{p}$ :

Let two $Z$-perspective 5-gons $\left\{A_{i}\right\},\left\{B_{i} \neq A_{i}\right\}$ be given in a projective $k$-space $(2 \leq k \leq 5)$, then, after interpreting this set of 11 points (which we assume to be different) as an axonometric fundamental figure of an axonometry $\alpha: \Pi^{5} \rightarrow \Pi^{\mathrm{k}}$, the originals $Z$ resp. $A_{i}$ resp. $B_{i}$ the homogenous coordinates $(1,0,0,0,0) \mathcal{F}$ resp. $\left(1, \delta_{1 i}, \ldots, \delta_{5 i}\right)$ and $\left(1,-\delta_{1 i},-\delta_{2 i},-\delta_{3 i},-\delta_{4 i},-\delta_{5 i},\right)$ form a 5 cross-polytope $\mathrm{P}_{10}$. By this we get 10 "direct" and 10 "overcrossing" Desargues points as follows (Table 2):

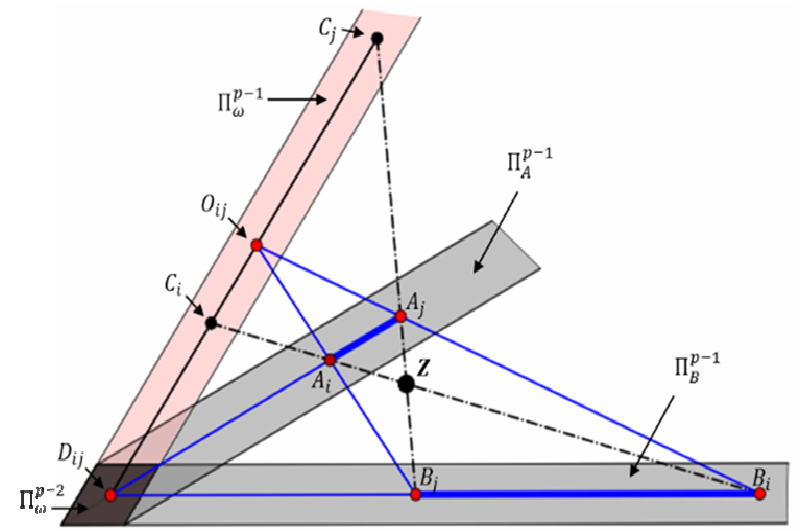

Figure 7. Symbolic visualisation of perspective p-simplexes and their "direct" and "overcrossing" Desargues points $D_{i j}$ and $O_{i j}$.

Table 2. : (Axonometric) projective coordinates of the direct and overcrossing Desargues points to perspective 5-gons

\begin{tabular}{|c|c|}
\hline$D_{12}=A_{1} A_{2} \cap B_{1} B_{2}=$ & $\mathrm{O}_{12}=A_{1} B_{2} \cap B_{1} A_{2}=$ \\
$=(0,1,-1,0,0,0) \mathcal{F}$ & $=(0,1,1,0,0,0) \mathcal{F}$ \\
\hline$D_{22}=A_{2} A_{2} \cap B_{2} B_{2}=$ & $\mathrm{O}_{22}=A_{2} B_{2} \cap B_{2} A_{2}=$ \\
$=(0,1,0,-1,0,0) \mathcal{F}$ & $=(0,1,0,1,0,0) \mathcal{F}$ \\
\hline$D_{14}=A_{1} A_{4} \cap B_{1} B_{4}=$ & $\mathrm{O}_{14}=A_{1} B_{4} \cap B_{1} A_{4}=$ \\
$=(0,1,0,0,-1,0) \mathcal{F}$ & $=(0,1,0,0,1,0) \mathcal{F}$ \\
\hline$D_{15}=A_{1} A_{5} \cap B_{1} B_{5}=$ & $\mathrm{O}_{15}=A_{1} B_{5} \cap B_{1} A_{5}=$ \\
$=(0,1,0,0,0,-1) \mathcal{F}$ & $=(0,1,0,0,0,1) \mathcal{F}$ \\
\hline$D_{22}=A_{2} A_{2} \cap B_{2} B_{2}=$ & $\mathrm{O}_{22}=A_{2} B_{2} \cap B_{2} A_{2}=$ \\
$=(0,0,1,-1,0,0,) \mathcal{F}$ & $=(0,1,1,0,0,0) \mathcal{F}$ \\
\hline$D_{24}=A_{2} A_{4} \cap B_{2} B_{4}=$ & $\mathrm{O}_{24}=A_{2} B_{4} \cap B_{4} A_{2}=$ \\
$=(0,1,0,0,-1,0) \mathcal{F}$ & $=(0,0,1,0,1,0) \mathcal{F}$ \\
\hline$D_{23}=A_{2} A_{3} \cap B_{2} B_{3}=$ & $\mathrm{O}_{23}=A_{2} B_{3} \cap B_{3} A_{2}=$ \\
$=(0,0,1,0,0,-1) \mathcal{F}$ & $=(0,0,1,0,0,1) \mathcal{F}$ \\
\hline$D_{24}=A_{2} A_{4} \cap B_{2} B_{4}=$ & $\mathrm{O}_{24}=A_{2} B_{4} \cap B_{4} A_{2}=$ \\
$=(0,0,0,1,-1,0) \mathcal{F}$ & $=(0,0,0,1,1,0) \mathcal{F}$ \\
\hline$D_{25}=A_{2} A_{5} \cap B_{2} B_{5}=$ & $\mathrm{O}_{25}=A_{2} B_{5} \cap B_{5} A_{2}=$ \\
$=(0,0,0,1,0,-1) \mathcal{F}$ & $=(0,0,0,1,0,1) \mathcal{F}$ \\
\hline$D_{45}=A_{4} A_{5} \cap B_{4} B_{5}=$ & $\mathrm{O}_{45}=A_{4} B_{5} \cap B_{5} A_{4}=$ \\
$=(0,0,0,0,1,-1) \mathcal{F}$ & $=(0,0,0,0,1,1) \mathcal{F}$ \\
\hline
\end{tabular}


From Table 2 follows that the ten triplets of direct Desargues points $\left(D_{i j}, D_{j k}, D_{i k}\right)$ are collinear with lines $d_{i j k}$ and that all those points $D_{i j}$ span a 3-space $\Pi_{\omega}^{3} \subset \Pi_{\omega}^{4} \subset \Pi_{\omega}^{5}$. As expected we find that the 10 points $D_{i j}$ and 10 lines $d_{i j k}$ form a Desargues configuration in $\Pi_{\omega}^{3}$ with five planes $Q_{\omega}^{m}, m=1, \ldots, 5,()(m \neq i \neq j \neq k \neq$ 1), containing 4 lines $d_{i j k}$ and six points $D_{i j}$. These five planes correlate to the five $Z$-perspective pairs of partial quadrangles $Q_{A}^{m}=A_{i} A_{j} A_{k} A_{l}, Q_{A}^{m}=B_{i} B_{j} B_{k} B_{l}$ of the given perspective 5-gons, and each of the pairs $\left(Q_{A}^{m}, Q_{B}^{m}\right)$ leads to a triplet of Ebisui points $\left(H_{1}^{m}, H_{2}^{m}, H_{3}^{m}\right)$ in the corresponding plane $Q_{\omega}^{3} \subset \Pi_{\omega}^{3}$ and a point $G^{m} \in \Pi_{\omega}^{4}$. We list the coordinates in Table 3:

Table 3. : (Axonometric) projective coordinates of the direct and overcrossing Desargues points to perspective 5-gons

\begin{tabular}{|c|c|c|c|c|c|c|c|c|c|c|c|}
\hline$\left(Q_{A}^{3}, Q_{B}^{3}\right)$ & $H_{2}^{3}=$ & $\left(\begin{array}{c}0 \\
1 \\
-1 \\
1 \\
-1 \\
0\end{array}\right)$ & $\mathcal{F}$ & $H_{2}^{3}=$ & $\left(\begin{array}{c}0 \\
1 \\
-1 \\
-1 \\
1 \\
0\end{array}\right)$ & $\mathcal{F}$ & $H_{2}^{3}=$ & $\left(\begin{array}{c}0 \\
1 \\
1 \\
-1 \\
-1 \\
0\end{array}\right)$ & $\mathcal{F}$ & $G^{3}=$ & $\left(\begin{array}{l}0 \\
1 \\
1 \\
1 \\
1 \\
0\end{array}\right)$ \\
\hline$\left(Q_{A}^{2}, Q_{B}^{2}\right)$ & $H_{2}^{4}=$ & $\left(\begin{array}{c}0 \\
1 \\
-1 \\
0 \\
1 \\
-1\end{array}\right)$ & $\mathcal{F}$ & $H_{2}^{4}=$ & $\left(\begin{array}{c}0 \\
1 \\
-1 \\
-1 \\
0 \\
1\end{array}\right)$ & $\mathcal{F}$ & $H_{2}^{4}=$ & $\left(\begin{array}{c}0 \\
1 \\
1 \\
-1 \\
0 \\
-1\end{array}\right)$ & $\mathcal{F}$ & $G^{4}=$ & $\left(\begin{array}{l}0 \\
1 \\
1 \\
1 \\
0 \\
1\end{array}\right)$ \\
\hline$\left(Q_{A}^{4}, Q_{B}^{4}\right)$ & $H_{2}^{2}=$ & $\left(\begin{array}{c}0 \\
1 \\
-1 \\
0 \\
1 \\
-1\end{array}\right)$ & $\mathcal{F}$ & $H_{2}^{2}=$ & $\left(\begin{array}{c}0 \\
1 \\
-1 \\
0 \\
-1 \\
1\end{array}\right)$ & $\mathcal{F}$ & $H_{2}^{2}=$ & $\left(\begin{array}{c}0 \\
1 \\
1 \\
-1 \\
-1 \\
0\end{array}\right)$ & $\mathcal{F}$ & $G^{2}=$ & $\left(\begin{array}{l}0 \\
1 \\
1 \\
0 \\
1 \\
1\end{array}\right)$ \\
\hline$\left(Q_{A}^{2}, Q_{B}^{2}\right)$ & $H_{2}^{2}=$ & $\left(\begin{array}{c}0 \\
1 \\
0 \\
-1 \\
1 \\
-1\end{array}\right)$ & $\mathcal{F}$ & $H_{2}^{2}=$ & $\left(\begin{array}{c}0 \\
1 \\
0 \\
-1 \\
-1 \\
1\end{array}\right)$ & $\mathcal{F}$ & $H_{2}^{2}=$ & $\left(\begin{array}{c}0 \\
1 \\
0 \\
1 \\
-1 \\
-1\end{array}\right)$ & $\mathcal{F}$ & $G^{2}=$ & $\left(\begin{array}{l}0 \\
1 \\
0 \\
1 \\
1 \\
1\end{array}\right)$ \\
\hline$\left(Q_{A}^{1}, Q_{B}^{1}\right)$ & $H_{1}^{2}=$ & $\left(\begin{array}{c}0 \\
0 \\
1 \\
-1 \\
1 \\
-1\end{array}\right)$ & $\mathcal{F}$ & $H_{1}^{2}=$ & $\left(\begin{array}{c}0 \\
0 \\
1 \\
-1 \\
-1 \\
1\end{array}\right)$ & $\mathcal{F}$ & $H_{1}^{2}=$ & $\left(\begin{array}{c}0 \\
0 \\
1 \\
1 \\
-1 \\
-1\end{array}\right)$ & $\mathcal{F}$ & $G^{1}=$ & $\left(\begin{array}{l}0 \\
0 \\
1 \\
1 \\
1 \\
1\end{array}\right)$ \\
\hline
\end{tabular}

From Tables 2 and 3 we read off that the ten lines $G^{m} G^{l}$ pass through $D_{m i}$ and that e.g. $H^{5}, O_{12}, O_{34}, G^{5}$ are collinear and harmonic, and we notice that e.g. the pair of Ebisui triangles $\left(H_{1}^{5} H_{2}^{5} H_{3}^{5}\right)$ and $\left(H_{1}^{2} H_{2}^{2} H_{3}^{2}\right)$ is $D_{34-}$ perspective. The "ideal points" $C_{i} \in \Pi_{\omega}^{4}$ of the five lines $A_{i} B_{i}$ are harmonic to $Z=(1,0, \ldots, 0) F$ with respect to $\left(A_{i} B_{i}\right)$ and they are therefore well defined also in the axonometric image space $\Pi^{\mathrm{k}}, 2 \leq k<5$.

The five pairs of points $\left(C_{i}, G^{i}\right)$ are in perspective position with the "unit point" $G=(0,1,1,1,1,1) \mathcal{F}$ $\in \Pi_{\omega}^{4}$. The quadruplets $\left(D_{12}, D_{13}, D_{14}, D_{15}\right)$ and $\left(O_{12}, O_{13}\right.$, $\left.O_{14}, O_{15}\right)$ are $C_{1}$-perspective and form a 4-cross-polytope $\mathrm{P}_{8}$ with centre $C_{1}$ and "ideal points" $\left(C_{2}, C_{3}, C_{4}, C_{5}\right)$ as expected.

Obviously there occur all together five such 4crosspolytopes and the points $C_{i}$ are their centres. The tetrahedron $\left(\mathrm{C}_{2}, \mathrm{C}_{3}, \mathrm{C}_{4}, \mathrm{C}_{5}\right)$ contains the octahedron $\left(\mathrm{O}_{23}\right.$, $\left.\mathrm{O}_{24}, O_{34}, O_{35}, O_{45}\right)$ as a cross-polytope $\mathrm{P}_{6}$ with centre $G^{1}$, see Figure 8.

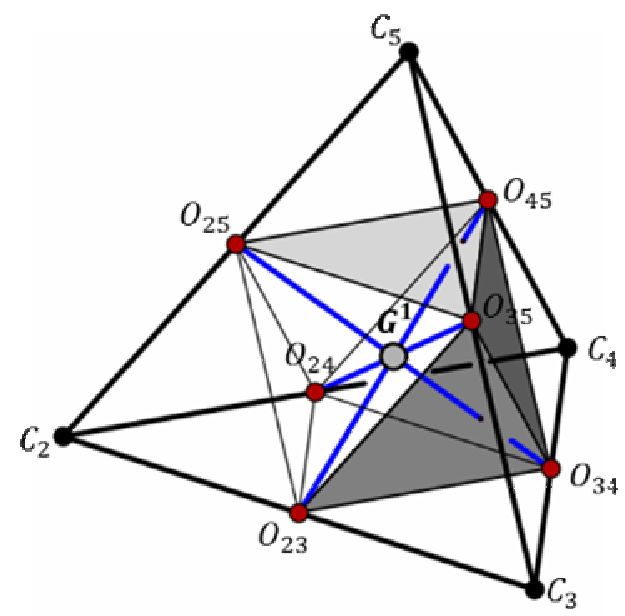

Figure 8. One of the five partial octahedra within the set of 10 "overcrossing" Desargues points $O_{i j}$.

These statements concerning incidences and relations occurring in a special-dimensional case should give sufficient insight into the combinatorial and analytic methods to treat also arbitrary dimensional cases. The occurrence of Desargues configurations and their higher dimensional analogues shall be mentioned in more detail in the next chapter.

\section{GENERALIZED DESARGUES CONFIGURATIONS AND CROSS-POLYTOPES}

In the former Chapters we found complete quadrilaterals (resp. quadrangles) and 3D-Desargues configuration connected with cross-polytopes. For such crosspolytopes one can present a list of facets in Table 4 (at the end of text), see also [7].

Each face-triangle or face-tetrahedron, together with "ideal" points and lines, gives rise to a complete facequadrilateral resp. a Desargues configuration in the projective extended 3-space spanned by the facetetrahedron.

Similarly, a $k$-face-simplex, together with its ideal elements, defines what might be called a " $i$ - Desargues configuration" generalizing the standard case to higher dimensions. Also here the system of incidences shall be shown in a Table 5 (also at the end of text). 
Table 4. Numbers of $k$-facets of a cross-polytope $P_{2 n}$

\begin{tabular}{|c|c|c|c|c|c|c|c|c|c|}
\hline $\operatorname{dim}$ & name & points & lines & 2-facets & 3-facets & 4-facets & 5-facets & 6-facets & $n--1$ \\
\hline 1 & segment & 2 & 1 & & & & & & \\
\hline 2 & quadrangle & 4 & 4 & 1 & & & & & \\
\hline 3 & octahedron & 6 & 12 & 8 & 1 & & & & \\
\hline 4 & 16-cell & 8 & 24 & 32 & 16 & 1 & & & \\
\hline 5 & Pentacross & 10 & 40 & 80 & 80 & 32 & 1 & & \\
\hline 6 & Hexacross & 12 & 60 & 160 & 240 & 192 & 64 & 1 & \\
\hline 7 & Heptacross & 14 & 84 & 280 & 560 & 672 & 448 & 128 & 1 \\
\hline $\bar{\vdots}$ & $\vdots$ & $\bar{\vdots}$ & $\bar{\vdots}$ & $\bar{\vdots}$ & & & & & \\
\hline$n$ & $n$-Cross & $\begin{array}{c}\text { points } \\
2 n\end{array}$ & $\begin{array}{l}\text { lines } \\
4\left(\begin{array}{l}n \\
3\end{array}\right)\end{array}$ & $\begin{array}{l}\text { planes } \\
8\left(\begin{array}{l}n \\
4\end{array}\right)\end{array}$ & & $2^{k+1}$ &,$k<n$ & & $\begin{array}{c}(n-1)- \\
\text { facets: } \\
2^{n}\end{array}$ \\
\hline
\end{tabular}

Table 5. Numbers of incident subspaces within $k$-dimensional generalized Desargues configurations

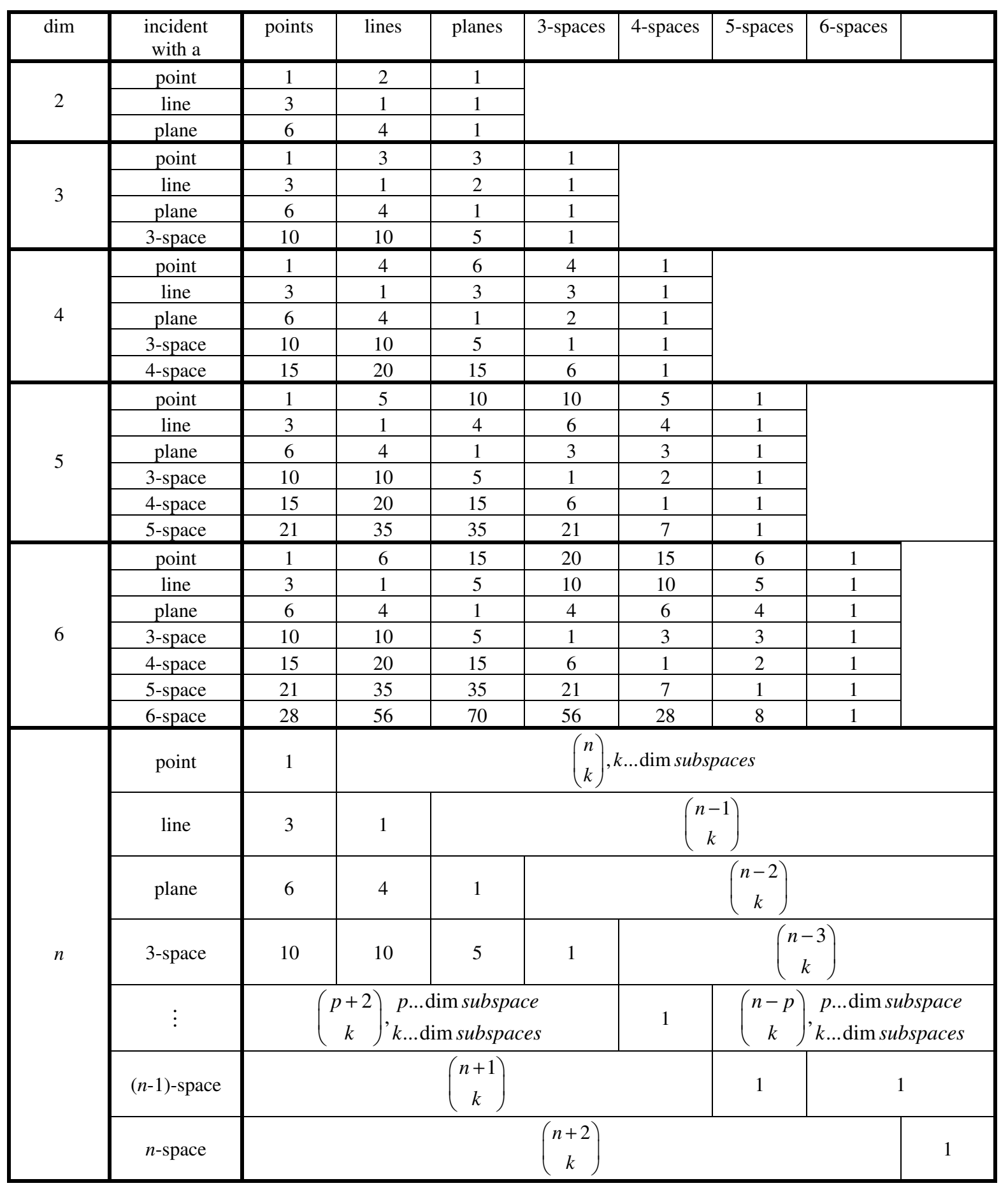




\section{CONCLUSION}

Starting from the discovery of a "remarkable point" occurring at perspective quadrangles in the projective enclosed Euclidean plane by the second author we could now generalize this fact to projective spaces over any coordinate field $\mathrm{F}$ with char $\mathrm{F} \neq 2$ and any dimension $\mathrm{n} \geq 2$.

The key tool is the interpretation of the given pair of perspective p-gons as axonometric fundamental figure of a central axonometry mapping an affine crosspolytope of a p-dimensional projective enclosed affine space to the given pair of p-gons in the k-space spanned by them. As the axonometric coordinate path in the image k-space uses the same projective coordinates as are used in the original p-space, the calculation of occurring incidences acts on Zeroes and Ones alone.

\section{ACKNOWLEDGMENT}

The first author was supported in parts by the University of Tokyo during a stay in March 2011.

\section{REFERENCES}

[1] Brauner, H.: Geometry of Projective Spaces I \& II (Geometrie Projektiver Räume I,II). BI Wissenschaftsverlag, Mannheim/Wien/Zürich 1976, 3-41101512-8 and 3-411-01513-6 Hochschultaschenbuch

[2] Havlicek, $\mathrm{H}$ : On the matrices of central linear mappings, Math. Bohem. 121 (1996), 151-156.

[3] Stachel, H.: More-dimensional Axonometry (Mehrdimensionale Axonometrie), in: N.K. Stephanidis (ed.), Proceedings of the Congress of Geometry, Thessaloniki 1987, 159-168.

[4] Stachel, H.,: On Arne Dür's equation concerning central axonometries, J. Geom. Graphics 8 (2004), 215-224.
[5] Stachel, H., Szabó, J. and Vogel, H.: A Theorem on Central Axonometry (Ein Satz über die Zentralaxonometrie), Sb. österr. Akad. Wiss., math.naturw. Kl., Abt.II 203 (1994), 3-11.

[6] Weiss, G., Manhart, F.: About some mappings defined by a classical Desargues configuration. Journal for Geometry and Graphics vol. 16 (2012), Nr. 2, p. 1-12

[7] https://en.wikipedia.org/wiki/Cross-polytope (retrieved April 18, 2016).

\section{ЗАПАЖАЊА О ПЕРСПЕКТИВНИМ СИМПЛЕКСИМА}

\section{Г. Вајс, Х. Ебисуи}

Два троугла једне равни која су у перспективном положају се повезују са Дезарговом теоремом која је заслужна за чињеницу да скуп координата у равни представља поље. Ова позната теорема омогућава очигледно тумачење тростране пирамиде у простору коју секу две равни.

Овај чланак је посвећен генерализацији Дезаргове теореме на перспективне симплексе у пројективном н-простору и њихових линеарних ликова у потпростору. На овај начин могу се открити значајне инциденције и конфигурације. Полазна тачка у овом истраживању је равни лик перспективних четвороуглова у коме је други аутор овог рада открио изузетно неочекивани лик. Доказ за ово изузетно тврђење се заснива на тумачењу равног лика бога Ебису као централне пројекције (пројективног) октаедра у 4Д простору. Овај принцип се може проширити и на већи број димензија. 